\title{
Transposição do Rio São Francisco: avaliação da influência do Rio Pajeú na qualidade da água da captação do eixo leste
}

\author{
Transposition of the São Francisco River: evaluation of the \\ influence of the Pajeú River in the water quality of the east side
}

Karina Waleska Lopes Rossiter ${ }^{1}$ (D), Érika Alves Tavares Marques $^{1}$ (D), Maria do Carmo Martins Sobral ${ }^{1}$ (D), Iris Eucarís de Vasconcelos ${ }^{1}$ (1)

1Universidade Federal de Pernambuco, Recife, PE, Brasil. E-mails: karinawlr@hotmail.com, erikatmbio@gmail.com, maria.msobral@ufpe.br, irisufpe@gmail.com

\begin{abstract}
Como citar: Rossiter, K. W. L., Marques, E. A. T., Sobral, M. C. M., \& Vasconcelos, I. E. (2021). Transposição do Rio São Francisco: avaliação da influência do Rio Pajeú na qualidade da água da captação do eixo leste. Revista de Gestão de Água da América Latina, 18 , e25. https://doi.org/10.21168/rega.v18e25
\end{abstract}

RESUMO: A região do semiárido brasileiro sofre de uma grande escassez de água. Para minimizar este problema o Governo Federal implementou um projeto de transposição de água do Rio São Francisco, através de dois eixos (Norte e Leste). 0 Rio São Francisco é um rio principal que percorre sete estados do Brasil. Seu maior tributário no estado de Pernambuco é o Rio Pajeú, que desagua no reservatório de Itaparica, num ponto a montante da captação do Eixo Leste da transposição. Esta pesquisa teve como objetivo avaliar se o aporte do Rio Pajeú pode influenciar na qualidade da água no trecho da captação do Eixo Leste. Durante o período da pesquisa a vazão do rio diminuiu 56,5\%. Os parâmetros: nitrito, nitrato, amônia, fósforo total, oxigênio dissolvido, DBO, DQO, pH, condutividade elétrica e clorofila-a foram monitorados em duas campanhas anuais entre 2011 e 2014. Os dados foram avaliados e comparados aos padrões da Resolução CONAMA 357/2005, sendo calculado também o índice de estado trófico (IET). Os resultados sugerem que mesmo a vazão média do Rio Pajeú $\left(14,2 \mathrm{~m}^{3} \mathrm{~s}^{-1}\right)$ sendo menor que a vazão do reservatório de Itaparica $\left(1532,5 \mathrm{~m}^{3} \mathrm{~s}^{-1}\right)$, com suas maiores concentrações de DBO, DQO e condutividade, o aporte de suas águas pode contribuir negativamente para qualidade da água do Eixo Leste, caso a vazão do reservatório continue a diminuir. Os IETs de ambos os pontos de monitoramento foram próximos, mas o teor de fósforo total está acima dos limites da legislação específica. As atividades de agricultura irrigada e piscicultura são apontadas como as principais causas para os valores elevados de DBO, DQO e fósforo total. 0 monitoramento da qualidade da água do Eixo Leste propicia aos gestores o uso sustentável dos recursos hidricos.

Palavras-chave: Qualidade da Água; Avaliação Ambiental; Transposição de Bacias.

ABSTRACT: The Brazilian semiarid region suffers from severe water shortages. To minimize this problem, the Federal Government implemented a water transposition project for the São Francisco River, through two axes (North and East). The São Francisco River is a main river that runs through seven states in Brazil. Its largest tributary in the state of Pernambuco is the Pajeú River, which flows into the Itaparica reservoir, at a point upstream of the East Axis catchment of the transposition. This research aimed to evaluate if the contribution of the Pajeú River could influence the water quality in the East Axis catchment stretch. During the research period, the river flow decreased by $56.5 \%$. The parameters nitrite, nitrate, ammonia, total phosphorus, dissolved oxygen, BOD, COD, pH, electrical conductivity, and chlorophyll $a$ were monitored, with two annual samplings between 2011 and 2014. The data were evaluated and compared to the standards specified in CONAMA Resolution 357/2005. Subsequently, the trophic status index (TSI) was calculated. The results suggest that even the average flow of Pajeú River $\left(14.2 \mathrm{~m}^{\mathrm{s}} \mathrm{s}^{-1}\right)$ being smaller than the flow of Itaparica reservoir $\left(1532,5 \mathrm{~m}^{3} \mathrm{~s}^{-1}\right)$, with higher concentrations of BOD, COD and conductivity, the input of its waters can negatively contribute to the quality of East Axis water, if the reservoir flow continues to decrease. The IETs of both monitoring points were close, but the total phosphorus content is above the limits of the specific legislation. Irrigated agriculture and fish farming activities are identified as the main sources for the high values of BOD, COD and total phosphorus. The water quality monitoring of the East Axis provides managers to the sustainable use of hydric resources.

Keywords: Water Quality; Environmental Assessment; Watershed Transposition.

Recebido: Maio 05, 2021. Revisado: Setembro 14, 2021. Aceito: Novembro 02, 2021. 


\section{INTRODUÇÃO}

O gerenciamento dos recursos hídricos tem se tornado uma grande preocupação em diversas áreas, tais como abastecimento urbano e rural, agricultura, dessedentação animal, piscicultura, indústria, lazer, dentre outras, pois é necessário atender às diversas demandas. No Brasil, a Bacia Hidrográfica do Rio São Francisco é bastante extensa e dividida em regiões (Alto, Médio, Submédio e Baixo) que diferem bastante quanto à área e e disponibilidade hídrica, conforme Tabela 1.

Tabela 1 - Regiões Fisiográficas da Bacia Hidrográfica do Rio São Francisco.

\begin{tabular}{|c|c|c|}
\hline Região & Extensão (km) & Disponibilidade Hídrica $\left(\mathrm{m}^{3} \mathrm{~s}^{-1}\right)$ \\
\hline 1 Alto & 702 & 1.126 \\
\hline 2 Médio & 1.230 & 2.508 \\
\hline 3 Submédio & 440 & 2.612 \\
\hline 4 Baixo & 214 & 2.651 \\
\hline
\end{tabular}

Fonte: Comitê da Bacia Hidrográfica do Rio São Francisco (2016)

No Submédio da Bacia do Rio São Francisco tem-se parte da região semiárida do Nordeste, que apresenta escassez de água, onde as taxas de evapotranspiração são elevadas e a distribuição irregular da precipitação é marcada por sua variabilidade espaço temporal, ocorrendo períodos prolongados de estiagens (Sobral et al., 2018).

Segundo Cirilo (2015), historicamente, os maiores deficits hídricos do Brasil são registrados no Nordeste, em sua porção semiárida, região ciclicamente submetida à ocorrência de secas. No semiárido, parte dos afluentes do Médio e do Submédio São Francisco apresentam regime de escoamento intermitente, o que leva à dinâmica de transporte de materiais e de diluição de cargas diferente das dos rios de escoamento perene. De acordo com os dados históricos, ocorreram 124 períodos de seca nos últimos quatro séculos, sendo grande parte destes eventos ligados ao fenômeno atmosférico oceânico El Niño (Silva \& Azevedo, 2020).

O Submédio da Bacia Hidrográfica do Rio São Francisco apresenta várias fontes de poluição, dentre elas destacam-se a agricultura irrigada, os esgotos domésticos, as atividades agropecuárias, e mais recentemente a piscicultura. A coleta e o tratamento de esgotos sanitários são deficientes, e, além disso, observa-se o lançamento de efluentes industriais e a disposição inadequada de resíduos sólidos, comprometendo a qualidade de rios (Agência Nacional de Águas, 2014).

O Rio São Francisco é um rio principal, recebendo em toda a sua extensão água de 168 afluentes divididos entre as suas margens esquerda e direita. No estado de Pernambuco o principal afluente é o Rio Pajeú, que desagua no reservatório de Itaparica.

Projetos onde as águas de uma bacia hidrográfica são transferidas para outras são denominados de integração ou transposição de bacias hidrográficas e, grosso modo, servem para aumentar a quantidade de recursos na bacia receptora ou a sua qualidade através da diluição das águas. Nestes projetos o planejamento e gestão de diversos fatores são apontados como características primordiais para a determinação de seu sucesso, como exemplo, as medidas com base legal e institucional, a participação popular, fatores econômicos e os impactos ambientais que este projeto pode causar desde sua concepção até o funcionamento (Andrade et al., 2011).

Nos tempos modernos, a principal motivação para a transferência de água entre as bacias nas regiões áridas e semiáridas é a chamada segurança hídrica, cujo objetivo básico é aumentar o nível de garantia de suprimento de água para as atividades a que se destina. Tais ações são sustentadas no princípio geral de equidade no direito do acesso à água, principalmente no que se refere ao abastecimento humano e animal, assegurado como princípio moral e incorporado na legislação das nações.

As transferências de águas entre bacias hidrográficas no contexto internacional e nacional têm como importante ator central o Banco Mundial e suas atividades no setor hídrico. Como exemplos de atuação do Banco no financiamento de transferência de águas entre bacias hidrográficas citam-se, no plano internacional, o Wanjiazhai Water Transfer Project (WWTP), na China, e o Lesotho Highlands Water Project, em Lesoto, Centro-Leste da África do Sul (Pires, 2019).

No Brasil, o Banco Mundial financiou o Projeto de Gerenciamento e Integração dos Recursos Hídricos (PROGERIRH), criado pelo Governo do Ceará em 1997, abrangendo a interligação da Bacia do Rio Jaguaribe com as bacias da Região Metropolitana de Fortaleza, que também é abrangida pela transposição do São Francisco. Outras experiências em transposições entre bacias hidrográficas têm como exemplo os Sistemas 
Alto Tietê-Baixada Santista e Rio Piracicaba-Alto Tietê (Sistema Cantareira), em São Paulo, além da transposição do Rio Paraíba do Sul, envolvendo os estados do Rio de Janeiro, São Paulo e Minas Gerais. No Nordeste, tem-se o Sistema Curema-Mãe d'Água para as Várzeas de Souza, Paraíba (empreendimento associado à transposição do São Francisco), e a transposição do Rio Paraguaçu para abastecer a Região Metropolitana de Salvador (Azevedo et al., 2005).

A garantia do fornecimento de água com qualidade é uma das premissas do Projeto de Integração do Rio São Francisco com Bacias do Nordeste Setentrional (PISF) e o monitoramento para verificar essas condições é parte imprescindível da execução do Projeto. Os reservatórios são os pontos de fornecimento da água para as regiões beneficiárias, sendo o principal uso destinado o de abastecimento humano, portanto, as atividades realizadas nos seus entornos devem ser reguladas pelas gestões municipais em conjunto com os órgãos de recursos hídricos (Pires, 2019).

Proposto há mais de um século como solução dos problemas trazidos pela escassez de água no semiárido, a transposição do Rio São Francisco passou a ser implantada a partir de 2007 sob o nome oficial de PISF. Trata-se da maior obra de infraestrutura hídrica do país, projetada para transferir 26,4 $\mathrm{m}^{3} \mathrm{~s}^{-1}$ por dois eixos principais, denominados de Norte e Leste, no sentido de disponibilizar água para as diversas atividades econômicas e abastecimento (multiplos usos). Por estar inserido na área do Polígono das Secas, o projeto pretende oferecer parte da água do Rio São Francisco aos rios temporários e açudes do semiárido (Brasil, 2004).

0 volume transportado pelos canais é destinado aos múltiplos usos: agricultura, consumo humano e dessedentação animal. Um aspecto que merece ser destacado sobre o empreendimento é aquele referente à dinamização da economia regional, a partir de um reforço à atividade agrícola e incorporação de novas áreas ao processo produtivo (Rodrigues \& Luz, 2021).

O Eixo Norte (captação próxima à cidade de Cabrobó-PE) levará água para os sertões de Pernambuco, Ceará, Paraíba e Rio Grande do Norte, e o Eixo Leste (captação no reservatório de Itaparica), que beneficiará parte do Sertão e a região Agreste de Pernambuco e da Paraíba. Espera-se que através da Transposição as demandas hídricas da população da região possam ser atentidas. As demandas hídricas referem-se às áreas urbanas dos municípios beneficiados, distritos industriais, perímetros de irrigação e usos difusos ao longo dos canais e rios perenizados por açudes existentes que receberão águas do Rio São Francisco (Castro, 2011).

Não apenas a quantidade, mas também a qualidade dos recursos hídricos é importante para atender às múltiplas demandas. Na avaliação da qualidade da água, os estudos de mapeamento do uso e ocupação do solo, representam importantes instrumentos para o planejamento, a avaliação e o monitoramento, a fim de garantir a conservação de seus recursos naturais (Sobral et al., 2018).

Além da análise dos parâmetros físico-químicos, o cálculo de alguns índices ajuda a interpretar a qualidade da água, como por exemplo, o índice de estado trófico, baseado nas concentrações de fósforo e clorofila-a. Assim, a qualidade da água nos pontos de captação dos Eixos Norte e Leste é de suma importância para garantir que ao chegar aos pontos de consumo, a mesma possa ser utilizada de acordo com o fim proposto.

O Rio Pajeú é o maior tributário do reservatório de Itaparica, desaguando a montante do ponto de captação do Eixo Leste, podendo seu aporte ter alguma influência na qualidade da água. Desta forma, o objetivo desse estudo é, através de ferramentas estatísticas, avaliar se o aporte do Rio Pajeú impacta negativamente na qualidade da água próximo à captação do Eixo Leste, incluindo também a influência no estado de trofia.

\section{MATERIAL E MÉTODOS}

\section{Área de estudo e pontos de monitoramento}

Ilustrada na Figura 1, a Bacia Hidrográfica do Rio São Francisco possui $639.219 \mathrm{~km}^{2}$ de área de drenagem (cerca de 8\% do País), abrangendo 521 municípios em sete unidades da Federação - Bahia (48,2\%), Minas Gerais (36,8\%), Pernambuco (10,9\%), Alagoas (2,2\%), Sergipe (1,2\%), Goiás (0,5\%), e Distrito Federal (0,2\%) (Agência Nacional de Águas, 2014). Devido à sua extensão e aos diferentes ambientes que percorre, a Bacia do São Francisco está subdividida em quatro regiões fisiográficas, que são Alto, Médio, Submédio e Baixo São Francisco (Brasil, 2006). Uma das características marcantes da Bacia do Rio São Francisco é o notório uso múltiplo de suas águas, preconizado na Lei no 9.433/1997, que ocorre para as mais diversas atividades: abastecimento populacional, irrigação, geração de energia, navegação, saneamento, pesca e piscicultura, atividades turísticas e de lazer (Companhia de Desenvolvimento dos Vales do São Francisco e do Parnaíba, 2016). A realidade socioeconômica da Bacia do Rio São Francisco apresenta grandes contrastes entre as 
regiões, entre os estados, entre os meios urbanos e rural e ainda entre as faixas de população, reproduzindo, assim, em grande medida, a desigualdade que ainda caracteriza a sociedade brasileira (Instituto Brasileiro de Geografia e Estatística, 2017).

O Rio São Francisco apresenta em sua calha principal uma série de reservatórios em cascata, desde o Alto São Francisco, com a represa de Três Marias, seguida por Sobradinho e Itaparica, até o Baixo São Francisco, com os reservatórios de Moxotó, Complexo de Paulo Afonso (PA I, II, III e IV) e Xingó, totalizando sete barragens de grande captação, das quais a barragem (reservatório) de Itaparica é a terceira maior em volume útil, inaugurada em 1988 (Agência Nacional de Águas, 2014).

No estado de Pernambuco, o maior afluente que desagua no reservatório Itaparica é o Rio Pajeú (Figura 1). O Rio Pajeú tem seu canal de escoamento no sentido Nordeste-Sudoeste e tem regime fluvial intermitente, percorrendo cerca de $353 \mathrm{~km}$ da nascente, na Serra do Balanço, no município de Brejinho, até a sua foz, no lago de Itaparica, no Rio São Francisco (Comitê da Bacia Hidrográfica do Rio São Francisco, 2016). De acordo com a classificação de Köppen, o clima dominante na região é semiárido com médias pluviométricas anuais inferiores a 800 mm (Freire \& Pachêco, 2011).

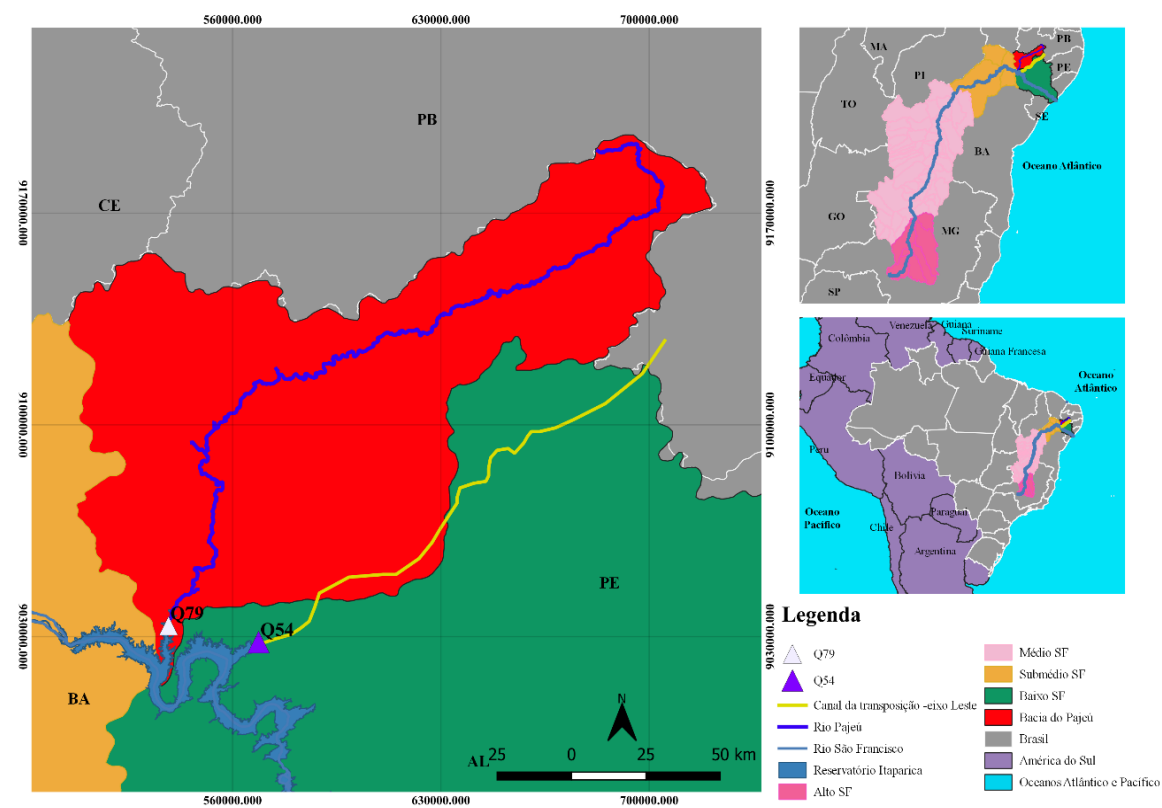

Figura 1 - Identificação da área de estudo com a localização dos pontos de amostragem. (adaptada de Comitê da Bacia Hidrográfica do Rio São Francisco, 2016).

Essa condição intermitente do Rio Pajeú se justifica pelo clima semiárido da área, com alta insolação, elevadas taxas de evaporação, baixa nebulosidade, além de regime de chuvas marcado pela escassez, irregularidade e concentração pluviométrica em curto período. A precipitação média anual é de $520 \mathrm{~mm}$, ocorrendo entre os meses de janeiro e abril. A temperatura média mensal é de $24^{\circ} \mathrm{C}$. A vegetação é a caatinga hiperxerófila, sendo especificamente arbórea e arbustiva na área estudada entremeadas de grandes áreas de solo exposto (Borges-Filho et al., 2014).

0 reservatório Itaparica localiza-se no trecho Submédio da Bacia do Rio São Francisco, entre os estados de Pernambuco e Bahia. Compreende área de $828 \mathrm{~km}^{2}$, extensão de aproximadamente $150 \mathrm{~km}$ e capacidade de armazenamento de 10,7 bilhões de $\mathrm{m}^{3}$, cujo nível pode variar até 5 metros, entre o nível operativo máximo de 304 m e mínimo de 299 m. 0 início da operacionalização da Usina Hidrelétrica Itaparica, também chamada de Usina Luiz Gonzaga ocorreu em 1988, com o objetivo de geração de energia elétrica e regularização das vazões afluentes aos reservatórios a jusante (Companhia de Desenvolvimento dos Vales do São Francisco e do Parnaíba, 2016). 0 reservatório de Itaparica tem características de usos múltiplos com a presença de tanques-rede para a produção de pescado, lazer, pesca, navegação, irrigação e utilização do potencial hidroelétrico (Ferreira, 2016).

A piscicultura é uma tecnologia de produção de peixe controlada e intensiva, que apoia a pesca artesanal limitada, mas com o aumento do nível de produção, o impacto nos ecossistemas aquáticos também aumenta. A utilização de gaiolas líquidas para piscicultura em lagos, reservatórios e zonas costeiras é a tecnologia mais simples para a produção de peixe, e é também o sistema mais utilizado 
nos reservatórios do Rio São Francisco (Silva et al., 2018). Segundo Gunkel et al. (2015), a piscicultura em tanques-rede é amplamente utilizada em reservatórios brasileiros, principalmente para a produção de tilápia. Os reservatórios presentes na Bacia do Rio São Francisco são vistos como tendo um elevado e crescente potencial de produção, principalmente o reservatório Itaparica.

Segundo Versyple et al. (2015) a microrregião apresenta clima quente, com períodos longos de estiagem e as chuvas irregulares variando entre os meses de janeiro e maio e a economia local se destaca pelo comércio, seguido da agropecuária que é a atividade mais desenvolvida do sertão brasileiro.

Os dados desta pesquisa fazem parte do Programa de Monitoramento da Qualidade da Água (PBA-22), realizado pelo ex-Ministério da Integração Nacional (atual Ministério do Desenvolvimento Regional), em atendimento à Licença de Operação do Instituto Brasileiro de Meio Ambiente - IBAMA, referente ao Projeto de Integração do Rio São Francisco com Bacias Hidrográficas do Nordeste Setentrional - PISF. Dentre os pontos de monitoramento do Programa PBA22, dois se enquadraram com o objetivo da pesquisa, bem como não havia um ponto intermediário entre eles. Os pontos monitorados foram o Q54 (reservatório de Itaparica- ponto de captação do Eixo Leste) e o Q79 (Rio Pajeú- único ponto do programa nesta área) ilustrados na Figura 1.

\section{Período de monitoramento e Coleta de Amostras}

Foram coletados dados da qualidade de água dos pontos monitorados referentes ao período de janeiro/2011 a setembro/2014, abrangendo coletas no período seco e outras no período chuvoso anualmente, perfazendo um total de oito coletas, conforme a Tabela 2.

Tabela 2 - Período das coletas.

\begin{tabular}{c|c|c|c|c|c|c|c}
\hline Coleta & Ano & Mês & Período & Coleta & Ano & Mês & Período \\
\hline 1 & 2011 & Fevereiro & Chuvoso & 5 & 2013 & Janeiro & Chuvoso \\
\hline 2 & 2011 & Outubro & Seco & 6 & 2013 & Setembro & Seco \\
\hline 3 & 2012 & Janeiro & Chuvoso & 7 & 2014 & Fevereiro & Chuvoso \\
\hline 4 & 2012 & Julho & Seco & 8 & 2014 & Setembro & Seco \\
\hline
\end{tabular}

As amostras de água foram coletadas na superfície, em frascos de plásticos ou vidros de $500 \mathrm{~mL}$, previamente higienizados e posteriormente lavados com a própria água a ser coletada. Após a coleta as amostras foram identificadas e acondicionadas em isopor com gelo triturado e enviadas para análise no laboratório no mesmo dia. Foram utilizadas as seguintes técnicas de preservação: resfriamento, congelamento e adição química. No caso dos ensaios físico-químicos, os frascos de coleta tinham preservante para se evitar possíveis alterações decorrentes de processos de precipitação, oxidação, adsorção, entre outros.

Os parâmetros analisados e suas metodologias estão detalhadas na Tabela 3. Os resultados obtidos na pesquisa foram comparados com a Resolução 357 do Conselho Nacional de Meio Ambiente - CONAMA (Brasil, 2005), que dispõe sobre a classificação dos corpos de água e diretrizes para o seu enquadramento. A área de estudo é enquadrada atualmente como água doce Classe 2, sendo este o parâmetro adotado para a avaliação dos resultados desta pesquisa.

Tabela 3 - Métodos analíticos utilizados de acordo com cada parâmetro.

\begin{tabular}{|c|c|}
\hline Parâmetro & Método \\
\hline $\begin{array}{l}\text { Clorofila-a } \\
\text { Demanda Bioquímica de Oxigênio (DBO) } \\
\text { Demanda Química de Oxigênio (DQO) }\end{array}$ & $\begin{array}{c}10220 \mathrm{H} \\
5210 \mathrm{D} \\
5520 \mathrm{D} \\
\text { (Standard Methods- American Public Health Association, 2005) }\end{array}$ \\
\hline Condutividade elétrica (CE)- in loco & Sonda multi-paramétrica, marca Horiba, mod.B-213 \\
\hline Fósforo total (PT) & $\begin{array}{c}\text { 4500- P B e D. Colorimétrico } \\
\text { (Standard Methods- American Public Health Association, 2005) }\end{array}$ \\
\hline $\begin{array}{c}\text { Nitrato }\left(\mathrm{NO}_{3}^{-}\right) \\
\text {Nitrito }\left(\mathrm{NO}_{2}^{-}\right) \\
\text {Nitrogênio amoniacal }\left(\mathrm{NH}_{3}\right)\end{array}$ & $\begin{array}{c}\text { 4500- } \mathrm{NO}_{3}-\text { B Colorimétrico } \\
4500-\mathrm{NO}_{2}-\text { B Colorimétrico } \\
\left(4500-\mathrm{NH}_{3} \text { C 2005). Titulação. }\right. \\
\text { (Standard Methods- American Public Health Association, 2005) }\end{array}$ \\
\hline $\begin{array}{c}\text { Oxigênio dissolvido (OD)- in loco } \\
\mathrm{pH}-\text { in loco }\end{array}$ & $\begin{array}{l}\text { Sonda multi-paramétrica, marca Horiba, mod.B-213portátil, } \\
\text { marca Horiba, mod.B-213 }\end{array}$ \\
\hline
\end{tabular}




\section{Tratamento de Dados}

A estatística multivariada é um conjunto de métodos estatísticos utilizados em situações nas quais as variáveis são medidas simultaneamente, em cada elemento amostral. A Análise de Componentes Principais (ACP) é uma técnica de estatística multivariada de redução da dimensionalidade que permite projetar o máximo de informação no menor número possível de dimensões não correlacionadas. Em outras palavras, as n-variáveis originais geram, através de suas combinações lineares, n-componentes principais, cuja principal característica, além da ortogonalidade, é que são obtidos em ordem decrescente de máxima variância, ou seja, a componente principal 1 detém mais informação estatística que a componente principal 2, que por sua vez tem mais informação estatística que a componente principal 3 e assim por diante. Analisando-se os gráficos dos escores e dos pesos resultantes dessa análise, pode-se identificar facilmente padrões de associação e similaridade tanto entre amostras quanto entre variáveis (Gomes \& Cavalcante, 2017).

Em seguida, foi elaborada uma Análise de Componente Principal (ACP) entre os pontos monitorados, sendo utilizada a cor azul para o período chuvoso e a vermelha para o seco. Para os parâmetros indicados na ACP como significativos foram elaborados diagramas de caixa (gráficos boxplot), destacando os valores de mediana, máximo e mínimo, bem como também estes resultados foram comparados com os valores máximos permitidos pelo CONAMA 357 para a classe 2 (Brasil, 2005). Considerou-se como significativos os parâmetros com peso superior a 0,5 na primeira e na segunda componente principal.

Para avaliar o grau de trofia dos pontos monitorados, foram calculados os Índices de Estado Trófico (IET). 0 IET classifica os corpos de água em diferentes graus de trofia, avaliando a qualidade da água quanto ao enriquecimento por nutrientes e seu efeito relacionado ao crescimento excessivo do fitoplâncton (Agência Pernambucana de Águas e Climas, 2018).

0 Índice do Estado Trófico (IET) foi composto pelo Índice do Estado Trófico para o fósforo IET(PT) e o Índice do Estado Trófico para a clorofila-a -IET(CL), modificados por Lamparelli (2004). Consideram-se as Equações 1 a 4 para se avaliar os resultados da clorofila-a e do fósforo total, em ambientes lóticos e lênticos, respectivamente.

Rios (ambientes lóticos)

$$
\begin{aligned}
& \operatorname{IET}(C l)=10 \times(6-((0,7-0,6 \times(\ln C l)) \ln 2))-20 \\
& \operatorname{IET}(P T)=10 \times(6-((0,42-0,36 \times(\ln P T)) \ln 2))-20
\end{aligned}
$$

Reservatórios (ambientes lênticos)

$$
\begin{aligned}
& \operatorname{IET}(C l)=10 \times(6-((0,92-0,34 \times(\ln C l)) / \ln 2)) \\
& \operatorname{IET}(P T)=10 \times(6-((1,77-0,42 \times(\ln P T)) / \ln 2))
\end{aligned}
$$

Onde:

PT: concentração de fósforo total medida à superfície da água, em $\mu \mathrm{g} . \mathrm{L}^{-1}$;

$\mathrm{Cl}$ : concentração de clorofila-a medida à superfície da água, em $\mu \mathrm{g} . \mathrm{L}^{-1}$;

ln: logaritmo natural.

O IET é a média aritmética simples dos índices relativos ao fósforo total e a clorofila-a, segundo a Equação 5:

$$
\operatorname{IET}=[\operatorname{IET}(P T)+\operatorname{IET}(\mathrm{Cl})] / 2
$$

Os limites estabelecidos para as diferentes classes de trofia estão descritos na Tabela 4. 
Tabela 4 - Classes de estado trófico e suas características principais.

\begin{tabular}{|c|c|c|}
\hline $\begin{array}{l}\text { Valor } \\
\text { do IET }\end{array}$ & $\begin{array}{c}\text { Classes de } \\
\text { Estado Trófico }\end{array}$ & Características \\
\hline$\leq 47$ & Ultraoligotrófico & $\begin{array}{l}\text { Corpos d'água limpos, de produtividade muito baixa e concentrações } \\
\text { insignificantes de nutrientes que não acarretam prejuízos aos usos da água. }\end{array}$ \\
\hline $47<$ IET $\leq 52$ & Oligotrófico & $\begin{array}{l}\text { Corpos d'água limpos, de baixa produtividade, em que não ocorrem } \\
\text { interferências indesejáveis sobre os usos da água, decorrentes da } \\
\text { presença de nutrientes. }\end{array}$ \\
\hline $52<\mathrm{IET} \leq 59$ & Mesotrófico & $\begin{array}{l}\text { Corpos d'água com produtividade intermediária, com possíveis } \\
\text { implicações sobre a qualidade da água, mas em níveis aceitáveis, na } \\
\text { maioria dos casos. }\end{array}$ \\
\hline $59<\mathrm{IET} \leq 63$ & Eutrófico & $\begin{array}{l}\text { Corpos d'água com alta produtividade em relação às condições naturais, com } \\
\text { redução da transparência, em geral afetados por atividades antrópicas. }\end{array}$ \\
\hline $63<\mathrm{IET} \leq 67$ & Supereutrófico & $\begin{array}{l}\text { Corpos d'água com alta produtividade em relação às condições naturais, de } \\
\text { baixa transparência, em geral afetados por atividades antrópicas, onde } \\
\text { ocorrem alterações indesejáveis na qualidade da água, como a ocorrência } \\
\text { de florações de algas, e interferências nos seus múltiplos usos. }\end{array}$ \\
\hline$>67$ & Hipereutrófico & $\begin{array}{l}\text { Corpos d'água afetados significativamente pelas elevadas concentrações de } \\
\text { matéria orgânica e nutrientes, com comprometimento acentuado nos seus } \\
\text { usos, associado a episódios florações de algas ou mortandades de peixes, com } \\
\text { consequências indesejáveis para seus múltiplos usos, inclusive sobre as } \\
\text { atividades pecuárias nas regiões ribeirinhas. }\end{array}$ \\
\hline
\end{tabular}

Fonte: Companhia de Tecnologia de Saneamento Ambiental (2017).

Na pesquisa sobre os dados climáticos (temperatura do ar e pluviosidade) foram utilizadas as informações da estação pluviométrica mais próxima aos pontos de monitoramento da pesquisa no banco de dados do Sistema Integrado de Dados Ambientais (SINDA) do Ministério de Ciência e Tecnologia. A estação foi a PCD 32026 localizada na cidade de Floresta, Pernambuco (Latitude: -8.600, Longitude: -38.567), bem como outras fontes bibliográficas pertinentes. Para o levantamento da vazão do reservatório de Itaparica os dados foram coletados junto à Companhia Hidroelétrica do São Francisco (CHESF) e ao Operador Nacional do Sistema Elétrico (ONS).

\section{RESULTADOS E DISCUSSÃO}

Para verificar a influência do Rio Pajeú na qualidade da água da captação do Eixo Leste, foram avaliados os dados climáticos da região e os resultados obtidos nas análises físico-químicas durante as oito campanhas foram tratados primeiramente através de ACP e depois interpretados por gráficos boxplot, sendo ainda gerado o IET dos pontos ao longo dos quatro anos

\section{Dados climáticos}

No Nordeste, a variabilidade espacial e temporal da precipitação é determinante para caracterizar o clima local, além de ser a principal entrada no sistema hidrológico. Os dados levantados pela estação pluviométrica PCD 32026 estão representados nas Figuras 2a e 2b.
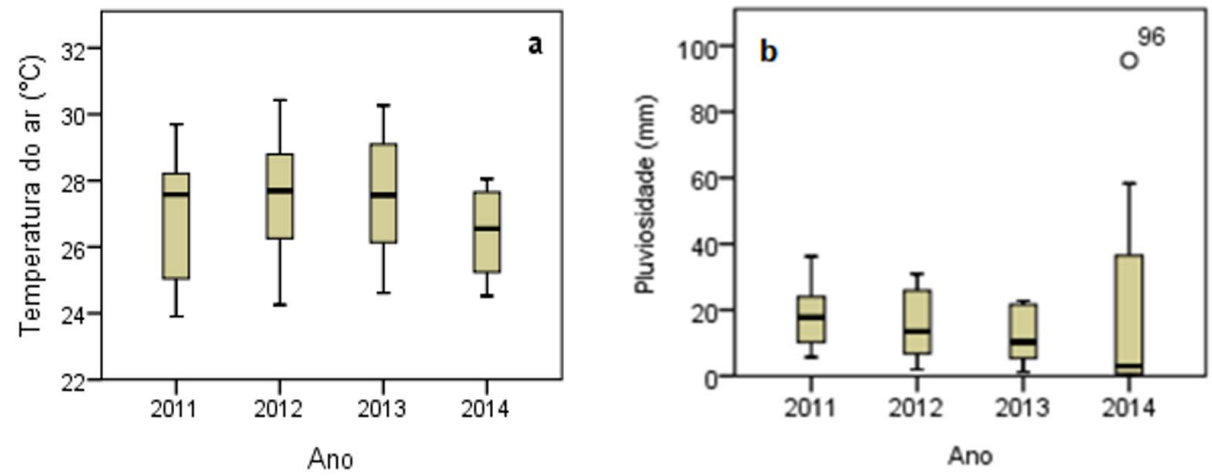

Figura 2 - Variação da temperatura média mensal do ar e da pluviosidade média mensal durante o período da pesquisa. 
Durante o período de estudo a temperatura média mensal do ar (Figura 2a) na região variou entre $23,9^{\circ} \mathrm{C}$ a $30,42^{\circ} \mathrm{C}$, mas as médias mensais ao longo do ano foram bastante próximas dentro quatro anos. A pluviosidade média mensal a região (Figura 2b) variou entre $0 \mathrm{~mm}$ e $96 \mathrm{~mm}$, apresentando valores próximos aos já relatados em outros trabalhos, apresentado uma mediana decrescente ao longo dos quatro anos. Esta tendência de menor precipitação foi relatada em diversos estudos.

Segundo Soares et al. (2018), através da aplicação do teste de Mann-Kendall em séries históricas de pluviometria do período de 1965 a 2014, de 12 localidades da Bacia do Rio Pajeú, os volumes anuais de precipitação estão diminuindo, os episódios de seca estão se tornando mais severos e está havendo uma tendência de mudança de categoria do clima semiárido (Índice de Aridez entre 0,20 e 0,50) para o árido (Índice de Aridez $<0,20$ ) na porção Sul da Bacia do Pajeú.

\section{Análise de Componentes Principais}

0 monitoramento da qualidade de água produz grande quantidade de dados, sendo vários parâmetros medidos em diversas amostras, coletadas em diferentes locais e durante campanhas de amostragem diferentes, cuja interpretação é complexa.

A Figura 3 apresenta o gráfico da ACP elaborado para avaliar a influência do aporte do Rio Pajeú(PA), que ao desaguar no reservatório de Itaparica segue o fluxo em direção ao ponto de captação do Eixo Leste também no reservatório de Itaparica(E). A Figura 3a apresenta o gráfico dos pesos dos escores das amostras. Os resultados obtidos referem-se às análises físico-químicas durante as oito campanhas. As duas primeiras componentes principais explicam $52,6 \%$ da variabilidade e foram considerados parâmetros significativos aqueles que pelo gráfico (Figura $3 \mathrm{~b}$ ) apresentaram pesos maiores que 0,5.
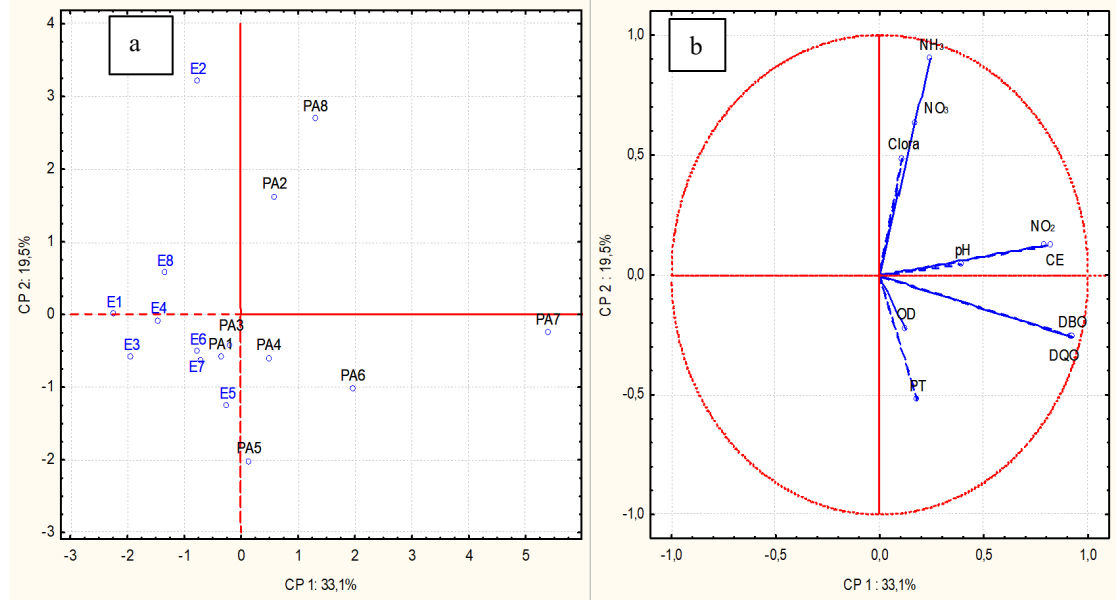

Figura 3 - Gráfico das duas primeiras componentes principais para as amostras do rio Pajeú (PA) e do ponto de captação do Eixo Leste (E) (a). gráfico dos pesos dos escores das amostras. (b) gráfico dos pesos dos parâmetros.

Através da distribuição das amostras na primeira componente principal, evidencia-se que para a maioria das coletas os dois pontos apresentam-se em quadrantes opostos, indicando características bem diferenciadas para os parâmetros de demanda bioquímica de oxigênio (DBO), demanda química de oxigênio (DQO), condutividade elétrica (CE) e nitrito $\left(\mathrm{NO}_{2}^{-}\right)$. A segunda componente principal caracterizou como parâmetros significativos a amônia $\left(\mathrm{NH}_{3}\right)$ e o nitrato $\left(\mathrm{NO}_{3}{ }^{-}\right)$.

Não houve separação distinta das amostras entre os períodos seco e chuvoso. Rossiter et al. (2020) ao estudar a mesma região, só que numa abrangência maior, também evidenciou que não houve diferenciação sazonal entre período seco e chuvoso.

Verificou-se que as amostras dos pontos monitorados são distintas, ou seja, as águas do Rio Pajeú apresentam características distintas do ponto Q54 no reservatório de Itaparica. Logo, o aporte das águas do rio Pajeú pode influenciar nas águas a jusante do seu ponto de descarga, pois o fluxo do rio é do ponto de desague do Rio Pajeú no sentido do ponto Q54.

Para os parâmetros destacados pela ACP como principais, foram elaborados gráficos do tipo boxplot, conforme a Figura 4, onde para aqueles parâmetros que existem especificações, os resultados são comparados com o valor máximo permitido (VMP) pelo CONAMA 357. Para os proximos gráficos adotaremos a identificaçao dos pontos conforme descrito na Figura 1 (Q79- Rio Pajeú, Q54 - captação do Eixo Leste no reservatório de Itaparica). 

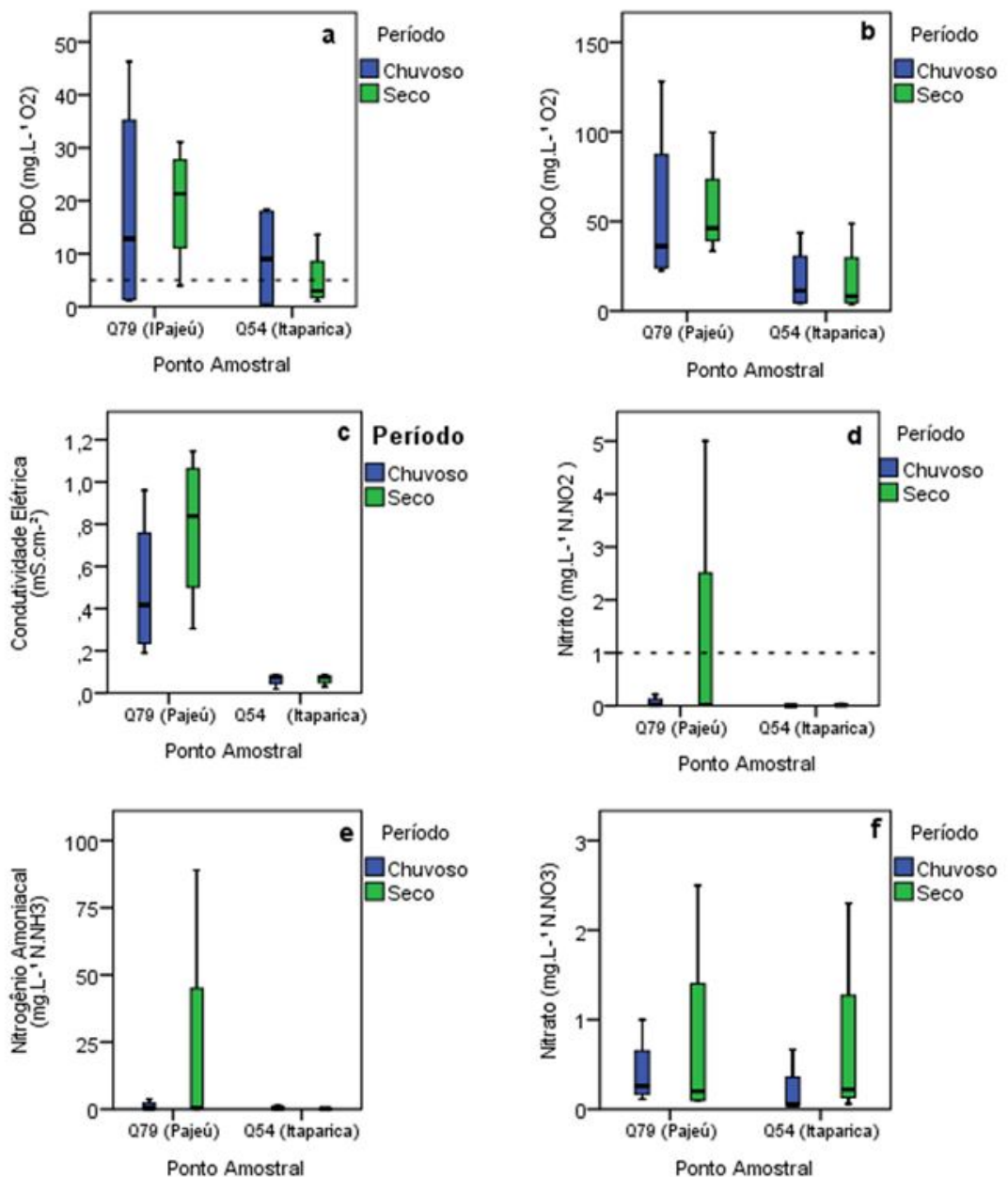

----- Valor Máximo Permitido pela Resolução CONAMA 357/2005.

Figura 4 - Variação sazonal dos parâmetros (a) DBO, (b) DQO, (c) Condutividade elétrica, (d) nitrito, (e) nitrogênio amoniacal e (f) nitrato, do reservatório Itaparica e do Rio Pajeú no período de estudo.

Observa-se na Figura 4a que as medianas da DBO, com exceção do período seco no reservatório de Itaparica, foram acima do limite do CONAMA 357 para águas de Classe $2\left(5 \mathrm{mg} \mathrm{L}^{-1} \mathrm{O}_{2}\right)$, indicando degradação na qualidade da água. Verifica-se também que os valores do rio Pajeú são superiores aos do reservatório de Itaparica. Para a DQO os resultados do Rio Pajeú também foram mais expressivos em ambos os períodos (Figura $4 \mathrm{~b}$ ).

Em geral, quando a região apresenta um período chuvoso (considerando uma precipitação elevada), também ocorre o aumento da concentração de nutrientes nas águas nas regiões de intensa atividade agrícola, em função dos processos de lixiviação dessas substâncias no solo. Contudo, os dados da pesquisa demonstram que nesta região com baixos níveis de pluviosidade (ver Figura 2b) e alta taxa de evaporação local, não houve esta caracterização de maiores valores no período chuvoso.

Na região próxima do Baixo São Francisco estudos relatados por Medeiros et al. (2016) durante os anos de 2001, 2004 e 2007, concluíram que a intensidade da precipitação teve um impacto direto sobre a qualidade da água, entretanto a localização geográfica da precipitação também foi um fator determinante para as alterações das características químicas e físicas da água que atinge a região inferior do rio São Francisco. Quanto maior a pluviosidade, maior a concentração dos nutrientes na água.

Os significativos valores de DQO e DBO no Rio Pajeú podem estar relacionados às condições de saneamento básico. De acordo com o Instituto Brasileiro de Geografia e Estatística (2018), o índice de esgotamento sanitário nos municípios da Bacia do Rio Pajeú varia de 14,2\% na cidade de Carnaubeira da Penha a 82,2\% na cidade de Itacuruba, que distam do ponto de coleta do rio Pajeú (Q79) $35 \mathrm{~km}$ e $38 \mathrm{~km}$, respectivamente. 
O índice de atendimento urbano dos serviços de saneamento (coleta de esgoto) do Submédio foi de 35,2\% em 2012, segundo dados do Sistema Nacional de Informações de Saneamento, do Ministério do Desenvolvimento Regional. Este índice quando comparado com as demais regiões da bacia é melhor do que região do Baixo São Francisco (6,7\%), próximo a do Médio $(35,75 \%)$ e bem abaixo da região do Alto São Francisco $(89,1 \%)$ (Comitê da Bacia Hidrográfica do Rio São Francisco, 2016).

Corroborando os resultados desta pesquisa, um estudo realizado por Cunha et al. (2019), na região do Rio Pajeú durante os anos de 2013/2014, também revelou resultados de DBO e DQO, acima do estabelecido pelo CONAMA 357 (Brasil, 2005), indicando como possíveis causas o desmatamento das matas ciliares, atividade agrícola e despejo de esgoto sem tratamento. Um segundo fator é que nas proximidades do Rio Pajeú há pastagens nas quais são criados animais domésticos, principalmente cavalos e gado bovino, gerando também um aporte de matéria orgânica para o rio (Silveira et al., 2013).

Durante o período de estudo o pH variou de levemente ácido $(6,02)$ a alcalino $(8,78)$. A condutividade elétrica (Figura 4c) do Rio Pajeú foi bem superior à do reservatório de Itaparica(Q54), principalmente no período seco, variando de 0,305 a $1,145 \mathrm{mS} . \mathrm{cm}^{-1}$. No reservatório de Itaparica a condutividade elétrica oscilou entre 0,018 e $0,085 \mathrm{mS} . \mathrm{cm}^{-1}$ durante toda a pesquisa. Em estudo realizado por Fernandes et al. (2009) ao longo do Rio Pajeú no período de junho de 2006 a março de 2007, os valores de pH variaram de 6,0 a 8,1 e a condutividade de 0,384 a 1,202 mS.cm-1 , valores que condizem com os resultados obtidos nesta pesquisa. Segundo, Fernandes et al. (2009) a alta condutividade está relacionada à baixa precipitação, à intemperização de rochas e ao tipo de solo e subsolo.

Quanto ao nitrito, ao verificar-se a Figura 4d, evidencia-se que as medianas em si foram próximas, apenas a amostra da sétima coleta (período chuvoso - 2014) do Rio Pajeú foi maior, mesmo assim muito abaixo do valor especificado no VMP do CONAMA 357/2005, que é de 1,0 mg L-1 $\mathrm{NO}_{2}{ }^{-}$. Logo, este parâmetro foi descaracterizado como fator diferencial entre os pontos de monitoramento. Ou seja, a contribuição dos nitritos oriundos das águas do Rio Pajeú não afetaria prejudicialmente as águas do reservatório de Itaparica.

A segunda componente da ACP indicou a amônia e o nitrato como parâmetros significativos. Ao observar as Figuras $4 \mathrm{e}$ e $4 \mathrm{f}$, evidencia-se que as medianas entre os pontos são próximas, tanto para o período seco e chuvoso. Logo, estes parâmetros não seriam um ponto impactante no aporte das águas do rio Pajeú.

Referente à vazão média da sub-bacia do Rio Pajeú, na atualização do Plano de Recursos Hídricos da Bacia do Rio São Francisco, a estimativa passou de $44,0 \mathrm{~m}^{3} \mathrm{~s}^{-1}$ para $14,2 \mathrm{~m}^{3} \mathrm{~s}^{-1}$, considerando o período de 1931-2013 (Bettencourt et al., 2016). Nos anos secos, o rio praticamente desaparece devido à alta evaporação típica da região semiárida $(2.000 \mathrm{~mm})$. Já em relação ao reservatório de Itaparica, as vazões afluente e defluente são representadas na Figura 5. Observa-se que ambas vazões são próximas e que houve uma redução significativa entre os anos de 2013 e 2014.

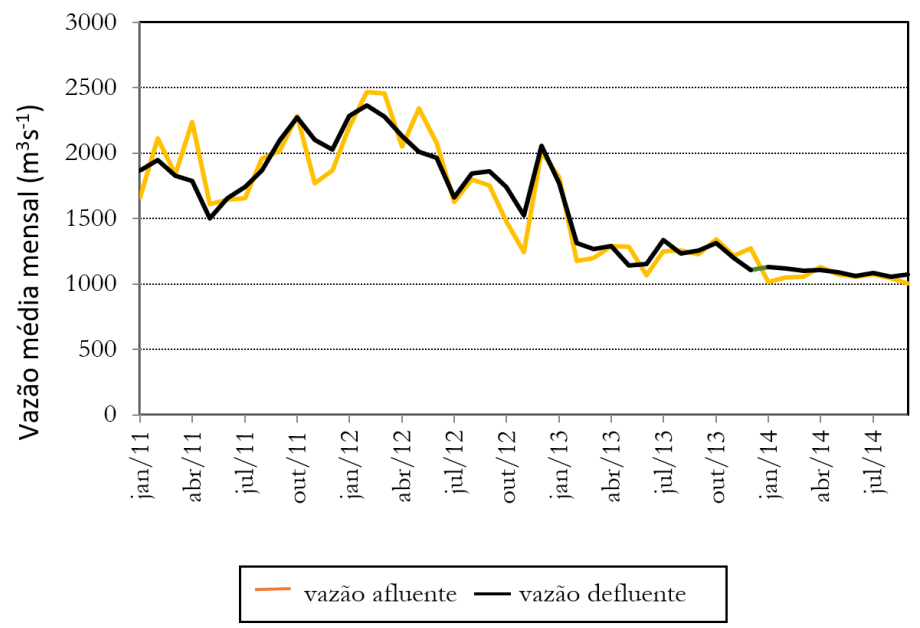

Figura 5 - Vazões médias afluentes e defluentes do reservatório de Itaparica entre janeiro/2011 e setembro/2014. Fonte: adaptado de Operador Nacional do Sistema Elétrico (2020)

Embora a vazão média do Rio Pajeú $\left(14,2 \mathrm{~m}^{3} \mathrm{~s}^{-1}\right)$ não seja alta em relação a vazão média do reservatório de Itaparica $\left(1532,5 \mathrm{~m}^{3} \mathrm{~s}^{-1}\right)$, com suas características DBO, DQO e condutividade elétrica, o aporte de suas águas para o reservatório de Itaparica tende a contribuir negativamente para qualidade 
da água do Eixo Leste nestes parâmetros, caso a vazão do reservatório continue a diminuir. Pela Figura 5, observa-se que a vazão média afluente do resevatório teve um perfil de descréscimo nos ultimos dois anos da pesquisa, saindo de $2056 \mathrm{~m}^{3} \mathrm{~s}^{-1}$ (dezembro de 2012) para $1007 \mathrm{~m}^{3} \mathrm{~s}^{-1}$ (setembro de 2014).

\section{Índice de Estado Trófico}

O Índice de Estado Trófico (IET) é um indice ambiental que classifica os corpos de água em níveis de trofia (enriquecimento de nutrientes), sendo os teores de fósforo e clorofila-a os parâmetros chave. Para avaliar qual a consequência do aporte do Rio Pajeú (Q79) no grau do estado trófico da água à jusante (Q54), foram calculados os IETs para os períodos seco (S) e chuvoso (C). Os resultados são apresentados na Figura 6 onde as siglas no eixo da esquerda representam os limites dos estados de trofia.

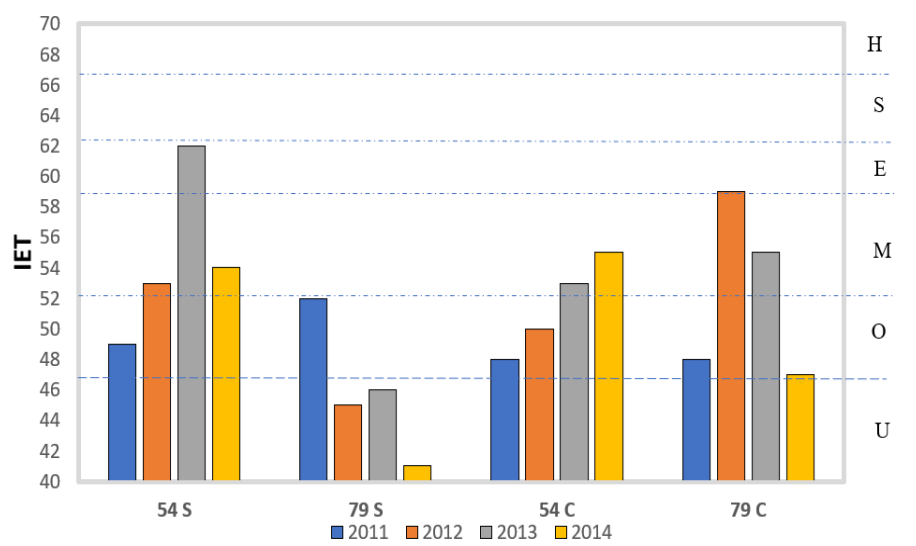

Figura 6 - Variação sazonal dos IETs dos pontos de monitoramento entre o período de 2011 a 2014 no periodo seco (S) e chuvoso. Legenda: H-Hipertrófico; S-Supereutrófico; E-Eutrófico; M-Mesotrófico; O-Oligotrófico; U- Ultraoligotrófico.

Durante o período seco o estado de trofia do Rio Pajeú (Q79) variou de 41 (Ultraoligotrófico) a 52 (Mesotrófico) e o ponto no reservatório Itaparica variou de 49 (Oligotrófico) a 62 (Supereutrófico). Para o período chuvoso o IET do Rio Pajeú variou de 47 (Oligotrófico) a 59 (Eutrófico), enquanto no ponto do reservatório de 48 (Oligotrófico) a 55 (Mesotrófico). Segundo Comitê da Bacia Hidrográfica do Rio São Francisco (2016), o IET da Bacia do Rio Pajeú em 2012 variou de mesotrófico a eutrófico, sendo coerente com os resultados obtido neste pesquisa.

Pode-se verificar que o estado de trofia do Rio Pajeú, ao longo dos quatros anos, não foi significativamente superior ao do ponto no reservatório de Itaparica (Q54). Isto sugere que, tanto no período chuvoso, onde o aporte de água do rio tributário é mais significativo, como no período seco o estado trófico do ponto de captação do Eixo Leste não sofreria aumento em função do aporte do Rio Pajeú.

Os resultados do fósforo total e da clorofila-a estão representados nas Figuras 7a e 7b, respectivamente. 0 Fósforo Total permaneceu acima do VMP da Resolução CONAMA 357 (Brasil, 2005) durante todo o período da pesquisa, que é de $0,050 \mathrm{mg} \mathrm{L}^{-1}$ para a Classe 2 . Tanto do período seco como no período chuvoso os valores no Rio Pajeú foram maiores que os do reservatório. Já para a clorofila-a os valores foram abaixo do valor máximo especificado na Resolução CONAMA que é de até $30 \mu g \mathrm{~L}^{-1}$.
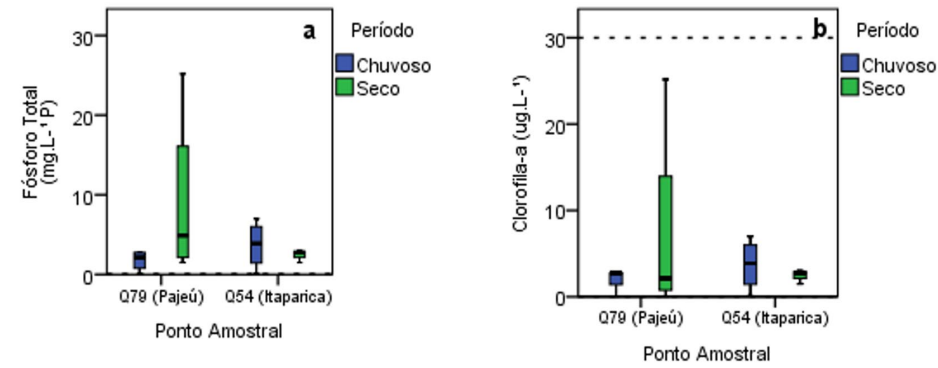

Figura 7 - Variação sazonal dos parâmetros de fósforo total (a) e clorofila a (b) no reservatório Itaparica e do Rio Pajeú no período de estudo. 
O aporte de fósforo na região em função da atividade pesqueira tem sido tema de alguns trabalhos. Matta et al. (2016) realizou simulações de hidrodinâmica e de transporte com o software de modelação TELEMAC-2D na baía de Icó-Mandantes, um ramo do reservatório de Itaparica, próximo a captação do Eixo Leste. As emissões de nutrientes de um hipotético sistema de aquacultura líquida localizado na baía foram investigadas em ciclos semestrais. Foi relatado neste estudo um impacto relevante na qualidade da água para uma produção de tilápia de 130 t y-1, ou seja, após 6 meses de simulação obtivesse cerca de $8 \mu \mathrm{g} \mathrm{P} \mathrm{L}{ }^{-1}$ e $6 \mu \mathrm{g} \mathrm{P} \mathrm{L}{ }^{-1}$ na fonte de emissões, para cenário de nível baixo e alto de água, respectivamente.

Os estudos de mapeamento do uso e ocupação do solo exercem também influência marcante sobre os recursos hídricos, uma vez que, representam importante instrumento para o planejamento e administração da ocupação do meio físico, possibilitando a avaliação e o monitoramento do mesmo, a fim de garantir a conservação de seus recursos naturais (Sobral et al., 2018).

De toda a vazão outorgada até 2014 na região do Submédio $\left(141,7 \mathrm{~m}^{3} . \mathrm{s}^{-1}\right)$, bem como na sub-bacia do Rio Pajeú $\left(3,31 \mathrm{~m}^{3} \cdot \mathrm{s}^{-1}\right)$ o uso na atividade de irrigação representa o maio percentual, conforme Figura 8 (Comitê da Bacia Hidrográfica do Rio São Francisco, 2016).

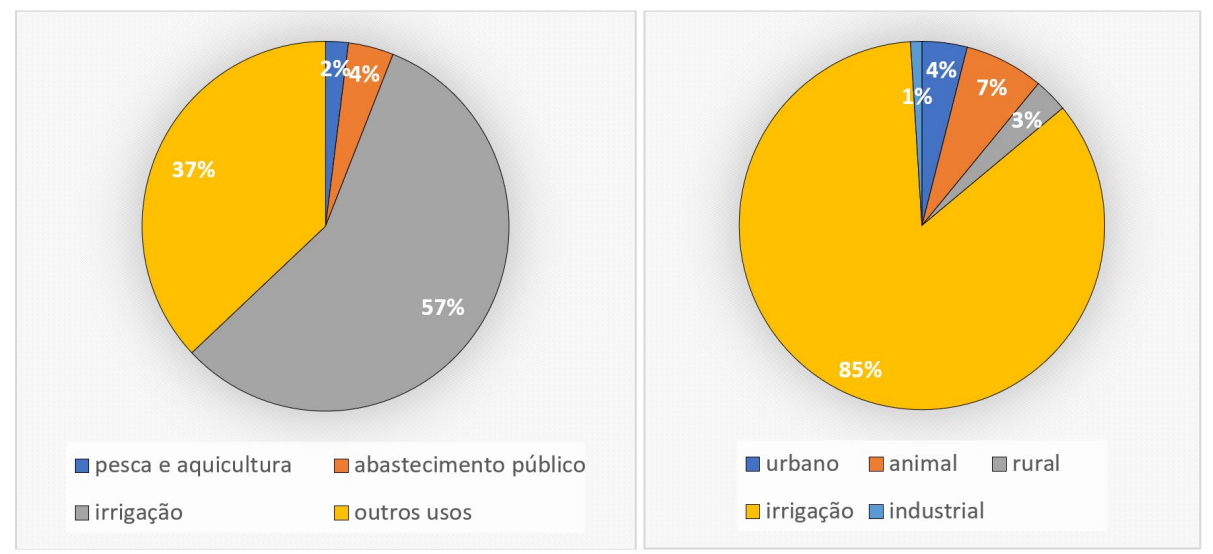

Figura 8 - Distribuição da vazão outorgada entre os diversos usos na região do Submédio(a) e na sub-bacia do Rio Pajeú. Adaptado pela Autora do Comitê da Bacia Hidrográfica do Rio São Francisco (2016).

O aumento da população e crescimento da agricultura, os problemas inerentes ao manejo inadequado do uso solo se intensificaram no entorno dos reservatórios, comprometendo a quantidade e qualidade hídrica.

Uma outra atividade econômica que vem crescendo muito na região é a piscicultura. Contudo, vários estudos têm apontado para impactos negativos na qualidade da água e na biodiversidade como resultado desta atividade de piscicultura, em função da sua intensidade, bem como do inadequado aporte de nutrientes (fósforo e nitrogênio).

Segundo Silva et al. (2018), a produção intensiva de pescado em tanques-rede é responsável por uma carga significativa de fósforo, nitrogênio e demanda biológica de oxigênio, promovendo o processo de eutrofização no reservatório de Itaparica. Derivado da alimentação, das fezes e ainda associados aos antibióticos e hormônios utilizados na criação dos peixes, são liberados diretamente nos corpos hídricos.

Em um estudo realizado por Gunkel et al. (2015), na baia de Icó-Mandantes dentro do reservatório de Itaparica e, próxima ao ponto de captação do Eixo Leste, a carga crítica de fósforo total do reservatório é 2,84 $\mathrm{g} \mathrm{m}^{-2} \mathrm{y}^{-1}$; sendo a carga real em 2015 já de 3,30 $\mathrm{g} \mathrm{m}^{-2} \mathrm{y}^{-1}$, estando o reservatório já sobrecarregado por nutrientes.

Os pontos de monitoramento foram considerados adequados, pois eram representativos do ponto de desague do Rio Pajeú e do ponto de captação do Eixo Leste.

\section{CONCLUSÃO}

A influência do aporte do Rio tributário Pajeú na qualidade hídrica do reservatório de Itaparica, foi analisada através da ACP, evidenciando-se que dentre os parâmetros estudados a demanda bioquímica de oxigênio (DBO), demanda química de oxigênio (DQO) e a condutividade elétrica seriam aqueles que exerceram o maior impacto.

As duas primeiras componentes principais da ACP explicaram 52,6\% da variabilidade total e destacaram cinco parâmetros significativos: DBO, DQO, condutividade, nitrato, nitrito e amônia. Após uma avaliação estatística destes parâmetros verificou-se que as medianas das concentrações de 
nitrito, nitrato e a amônia dos dois pontos de monitoramento eram próximas, não sendo então considerados como parâmetros que pudessem influenciar negativamente a qualidade da água do reservatório de Itaparica. Mesmo a vazão média do rio Pajeú $\left(14,2 \mathrm{~m}^{3} \mathrm{~s}^{-1}\right)$ sendo bem menor que a do reservatório de Itaparica $\left(1532,5 \mathrm{~m}^{3} \mathrm{~s}^{-1}\right)$, o aporte de suas águas com características de maior condutividade elétrica, DBO e DQO, pode vir a contribuir negativamente para qualidade da água do Eixo Leste, principalmente se a vazão do reservatório de Itaparica continuar a diminuir.

Também foi avaliado o grau do estado trófico (IET) e os resultados do Rio Pajeú encontravam-se num grau de trofia menor do que o reservatório de Itaparica, indicando que em relação aos nutrientes fósforo e a clorofila-a, seu aporte não afetaria de forma negativa. Contudo, os resultados do fósforo total permaneceram acima da especificação máxima da Resolução CONAMA 357/2005 durante todo o período da pesquisa, que é de $0,030 \mathrm{mg} \mathrm{L}^{-1}$ para a Classe $2 \mathrm{em}$ ambos os pontos de monitoramento.

As áreas do entorno do reservatório possuem atividades agropecuárias, particularmente a agricultura irrigada e de piscicultura, que contribuem para aumentar o risco de eutrofização pela utilização descontrolada de fertilizantes, agrotóxicos e pelo aporte dos resíduos gerados na criação dos peixes. 0 monitoramento destas atividades pelos Órgãos competentes é fundamental para garantir que a água captada no Eixo Leste apresente uma qualidade adequada para ser transposta e abastecer as demais regiões.

A situação de saneamento básico é outro aspecto ainda precário, que pode contribuir de forma negativa para a qualidade dos recursos hídricos da região. Os objetivos e as diretrizes gerais da Política Nacional de Recursos Hídricos fazem menção clara à gestão integrada de recursos hídricos, bem como às necessidades das gerações atual e futuras. 0 Objetivo do Desenvolvimento Sustentável (ODS) 6 chama a atenção das autoridades globais a respeito da necessidade do acesso à água potável e ao saneamento pelas populações de todo o mundo. Para que esse objetivo seja cumprido, há um conjunto de metas a considerar, entre as quais se destacam a melhoria da qualidade da água ofertada, o aumento da eficiência no uso desse recurso em todos os setores (incluindo o seu uso sustentável) e, ainda, a proteção ou restauração dos ecossistemas (Empresa Brasileira de Pesquisa Agropecuária, 2018).

\section{AGRADECIMENTOS}

Agradecemos o apoio a esta pesquisa, que no âmbito do projeto INNOVATE (Interplay among multiple uses of water reservoirs via innovative coupling of aquatic and terrestrial ecosystems), foi financiado pelo Conselho Nacional de Desenvolvimento Científico e Tecnológico (CNPq, 490003/2012-5), pelo Ministério Federal da Educação e Investigação alemão (BMBF, BMBF, Código de financiamento 01LL0904A) e pela Universidade Federal de Pernambuco (UFPE).

\section{REFERÊNCIAS}

Agência Nacional de Águas - ANA. (2014). Região hidrográfica São Francisco. Recuperado em 5 de maio de 2021, de http://www2.ana.gov.br/Paginas/portais/bacias/SaoFrancisco.aspx

Agência Pernambucana de Águas e Climas - APAC. (2018). Boletim de monitoramento de qualidade das águas dos reservatórios de Pernambuco (No. 5). Recuperado em 5 de maio de 2021, de http://www.apac.pe.gov.br/down/not_1043_15206213305aa2d71263238_boletim_de_monitoramento_de _qualidade_de_agua_n05.pdf

American Public Health Association - APHA. (2005). Standard methods for the examination of water and wastewater (21st ed.). Washington: APHA.

Andrade, J. G. P., Barbosa, P. S. F., Souza, L. C. A., \& Makino, D. L. (2011). Interbasin water transfers: the Brazilian experience and international case comparisons. Water Resources Management, 25(8), 1915-1934.

Azevedo, L. G. T., Porto, R. L., Méllo Júnior, A. V., Pereira, J. G., Arrobas, D. L. P., Noronha, L. C., \& Pereira, L. P. (2005). Transferência de água entre bacias hidrográficas. Brasília: Banco Mundial.

Bettencourt, P., Fulgêncio, C., Grade, M., Alcobia, S., Monteiro, J. P., Oliveira, R., Leitão, J. C., Leitão, P. C., Fernandes, P. A., Sousa, S., Brites, S., Fernandes, J., Simões, J., Scarton, M., Santiago, E., Aguiar, R., Giffoni, M., Melo, F., \& Paes, A. C. (2016). São Francisco river basin management plan. Revista Recursos Hídricos, 37(1), 73-80. http://dx.doi.org/10.5894/rh37n1-cti3

Borges-Filho, E. F. A., Selva, V. S. F., Soares, D. B., \& Cardoso, J. J. (2014). 0 recurso natural água no contexto da escassez: o uso de tecnologias sociais no alto trecho da Bacia do Rio Pajeú, Pernambuco. Revista Eletrônica do PRODEMA, 8(2), 6-19. Recuperado em 5 de maio de 2021, de http://www.revistarede.ufc.br/rede/article/view/238 
Brasil. (2004). RIMA - Projeto de Integração do Rio São Francisco com as Bacias Hidrográficas do Nordeste Setentrional. Brasília. DF: Ministério da Integração Nacional.

Brasil. Ministério do Meio Ambiente. (2005). Resolução CONAMA 357, de 17 de março de 2005 Conselho Nacional de Meio Ambiente. Diário Oficial [da] República Federativa do Brasil, Brasília. Recuperado em 5 de maio de 2021, de http://www.siam.mg.gov.br/sla/download.pdf?idNorma=2747

Brasil. Ministério do Meio Ambiente - MMA. (2006). Caderno da região hidrográfica do São Francisco (614p.). Brasília: Secretaria de Recursos Hídricos, Ministério do Meio Ambiente.

Castro, C. N. (2011). Transposição do Rio São Francisco: análise de oportunidade de projeto (Texto para Discussão, No. 1577). Rio de Janeiro: Instituto de Pesquisa Econômica Aplicada.

Cirilo, J. A. (2015). Crise hídrica: desafios e superação. Revista USP, (106), 45-58. http://dx.doi.org/10.11606/issn.2316-9036.v0i106p45-58

Comitê da Bacia Hidrográfica do Rio São Francisco - CBHSF. (2016). Plano de Recursos Hídricos da Bacia do Rio São Francisco 2016-2025 (Vols. 1-4, 520 p.). Alagoas: 0 Comitê.

Companhia de Desenvolvimento dos Vales do São Francisco e do Parnaíba - CODEVASF. (2016). Plano Nascente São Francisco: plano de preservação e recuperação de nascentes da bacia do rio São Francisco (130р.). Brasília-DF: Editora IABS.

Companhia de Tecnologia de Saneamento Ambiental - CETESB. (2017). Índices de qualidade das águas: apêndice $D$ (pp. 32). São Paulo: CETESB.

Cunha, A. M., Casé, M., \& Lopes, D. V. (2019). Qualidade da água como reflexo de atividades antrópicas em bacias hidrográficas do Nordeste, Brasil. Revista Geosul, 34(72), 102-123. http://dx.doi.org/10.5007/19825153.2019v34n72p102

Empresa Brasileira de Pesquisa Agropecuária - EMBRAPA. (2018). Água e saneamento: contribuições da Embrapa (104 p.). Brasília: Embrapa.

Fernandes, J. G., Freire, M. B., Cunha, J. C., Galvíncio, J. D., Correa, M. M., \& Santos, P. R. (2009). Qualidade físicoquímica das águas utilizadas no Perímetro Irrigado Cachoeira II, Serra Talhada, Pernambuco. Agrária, 4(1), 27-34. http://dx.doi.org/10.5039/agraria.v4i1a5

Ferreira, A. L. N. (2016). Análise integrada da qualidade de água dos corpos hídricos do Projeto de Integração do Rio São Francisco no Nordeste do Brasil (Tese de doutorado). Centro de Tecnologia e Geociências, Universidade Federal de Pernambuco, Recife.

Freire, N. C. F., \& Pachêco, A. P. (2011). Desertificação: análise e mapeamento (1. ed., Vol. 1). Recife, BRA: Editora Universitária da UFPE.

Gomes, M. C. R., \& Cavalcante, I. N. (2017). Application of Multivariate Statistical Analysis in the study of the quality of groundwater. Revista Águas Subterrâneas, 31(1), 134-149.

Gunkel, G., Matta, E., Selge, F., Silva, G. M. N., \& Sobral, M. C. (2015). Carrying capacity limits of net cage aquaculture for Brazilian reservoirs. Revista Brasileira de Ciências Ambientais, (36), 129-144. http://dx.doi.org/10.5327/Z2176-947820151008

Instituto Brasileiro de Geografia e Estatística - IBGE. (2018). Cidades. Informações dos municípios de Afogados da Ingazeira, Brejinho, Calumbi, Carnaíba, Flores, Iguaraci, Ingazeira, Itapetim, Quixaba, Santa Cruz da Baixa Verde, Santa Terezinha, São José do Egito, Serra Talhada, Solidão, Tabira, Triunfo e Tuparetama. Recuperado em 5 de maio de 2021, de https://cidades.ibge.gov.br/brasil/estado/municipio/panorama

Instituto Brasileiro de Geografia e Estatística - IBGE. Censo agropecúario 2017: resultado definito (Vol. 8, pp. 1105). 2017. Recuperado em 5 de maio de 2021, de https://biblioteca.ibge.gov.br/visualizacao/periodicos/3096/agro_2017_resultados_definitivos.pdf

Lamparelli, M. C. (2004). Grau de trofia em corpos d'água do estado de São Paulo: avaliação dos métodos de monitoramento (Tese de doutorado). Instituto de Biociências, Universidade de São Paulo, São Paulo.

Matta, E., Selge, F., Gunkel, G., Rossiter, K. W. L., Jourieh, A., \& Hinkelmann, R. (2016). Simulations of nutrient emissions from a net cage aquaculture system in a Brazilian bay. Water Science and Technology, 73(10), 2043-2049. http://dx.doi.org/10.2166/wst.2016.092

Medeiros, P. R. P., Cavalcante, G. H., Brandini, N., \& Knoppers, A. B. (2016). Variabilidade interanual na qualidade da água no Baixo Rio São Francisco (NE-Brasil). Acta Limnologica Brasiliensia, 28(5).

Operador Nacional do Sistema Elétrico - ONS. (2020). Histórico de operação: dados hidrológicos: vazões. Recuperado em 5 de maio de 2021, de http://www.ons.org.br/Paginas/resultados-da-operacao/historicoda-operacao/dados_hidrologicos_vazoes.aspx 
Pires, A. P. N. (2019). Estrutura e objetivos da transposição do rio São Francisco: versões de uma mesma história. Revista Geousp Espaço e Tempo, 23(1), 182-197.

Rodrigues, A. P., \& Luz, V. S. (2021). A estruturação do espaço urbano e regional a partir da transposição do Rio São Francisco (2007-2017). Revista Política e Planejamento Regional, 8(2), 233-252.

Rossiter, K. W. L., Marques, E. A. T. M., Oliveira, C. R., Matta, E., \& Moraes, M. M. Q. M. (2020). Spatial-temporal evaluation of water quality in Brazilian semiarid reservoirs. Water Practice \& Technology, 15(1), 92-104. http://dx.doi.org/10.2166/wpt.2020.001

Silva, F. J. B. C., \& Azevedo, J. R. G. (2020). Temporal trend of drought and aridity indices in semi-arid Pernambuco to determine susceptibility desertification. Brazilian Journal of Water Resources, 25, e32. http://dx.doi.org/10.1590/2318-0331.252020190145

Silva, G. M. N., Carvalho, R. M. C. M. O., El-Deir, A. C. A., Sobral, M. C., \& Siegmund-Schultze, M. (2018). Artisanal fisheries of the Itaparica reservoir, São Francisco River, Brazil: socioeconomic profile, environmental dynamics, and management recommendations. Regional Environmental Change, 18, 1-11. http://dx.doi.org/10.1007/s10113-018-1293-y

Silveira, R. L., Diniz, L. P., \& Pereira, L. A. N. (2013). Diagnóstico ambiental de trechos da bacia do Rio Pajeú (Serra Talhada, PE): montagem de banco de imagens e variáveis liminológicas. In Anais da XIII Jornada de Ensino, Pesquisa e Extensão (JEPEX). Recife: UFRPE.

Soares, D., Nobrega, R. S., \& Galvíncio, J. D. (2018). Indicadores climáticos de desertificação na bacia hidrográfica do rio Pajeú, Pernambuco. Revista Brasileira de Climatologia, 22, 363-380. http://dx.doi.org/10.5380/abclima.v22i0.58557

Sobral, M. C., Assis, J. M. O., Oliveira, C. R. O., Silva, G. M. N., Moraes, M. M., \& Carvalho, R. M. C. (2018). Impact of climate change on water resources in the subdom of the São Francisco River Basin - Brazil. Revista Eletrônica do PRODEMA, 12(3), 95-106. http://dx.doi.org/10.22411/rede2018.1203.10.

Versyple, N. I., Machado, J., Andrade, J. S. C., \& Wanderley, R. A. (2015). Microrregião Pajeú: economia, clima e desenvolvimento da agricultura através de modelo digital do terreno. Revista GEAMA, 1(1), 16-30. Recuperado em 5 de maio de 2021, de https://core.ac.uk/reader/228885544

\section{Contribuições dos autores:}

Karina Waleska Lopes Rossiter: responsável pela pesquisa, sendo a mesma parte da sua tese de doutorado.

Érika Alves Tavares Marques: participou no tratamento dos dados e discussão dos resultados.

Maria do Carmo Martins Sobral: coordenadora do Projeto de Pesquisa e revisora da parte técnica do artigo.

Iris Eucarís de Vasconcelos: revisou a parte da metodologia científica do artigo, bem como a parte de tratamento de dados. 